\title{
Nueva etapa de la Revista Iberoamericana de Cirugía de la Mano
}

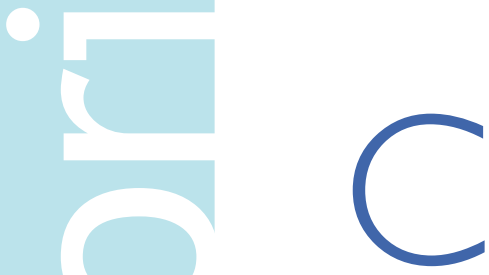

on el presente número de la Revista Iberoamericana de Cirugía de la Mano (RICMA), iniciamos una nueva etapa editorial. La RICMA se fundó por el Dr. Alfredo Quintana Montero en 1973, como Revista Española de Cirugía de Mano y era el órgano de expresión escrita de la Sociedad Española de Cirugía de Mano (SECMA). En 1998, siendo presidente el Dr. Higinio Ayala Palacios, por iniciativa del Dr. Carlos Irisarri y posterior aprobación por la Asamblea, se inició un proyecto de renovación de la Revista Española de Cirugía de la Mano con el propósito de que se integrasen otras sociedades científicas y pasó a denominarse Revista Iberoamericana de Cirugía de la Mano.

Desde su fundación hasta este momento, han sido cuatro equipos de dirección los que han contribuido al desarrollo y expansión de la RICMA y que tenga sociedades científicas afiliadas como la Asociación Argentina de Cirugía de la Mano (AACM), la Sociedad Portuguesa de Cirugía da mano (SPOCMA), la Sociedade Brasileira de Cirurgia da Mão y la Sociedad de Cirugía Plástica de Uruguay (sección mano). Estos cuatro grupos han sido formados por el Dr. Alfredo Quinana Guitián como redactor-jefe y los doctores Xavier Mir, Francisco del Piñal y José María Arandes como directores. A todos ellos, junto a los correctores que han participado en el proceso editorial, les debemos agradecer el esfuerzo y tiempo empleados en hacer de la RICMA una revista de gran interés para todos los cirujanos especializados en la patología de la mano, muñeca, codo y microcirugía.

En esta nueva andadura, que comenzamos con mucha ilusión, nos impulsa el reto de conseguir tres objetivos. El primero es sentar las bases para poder indexar la RICMA en PUBMED en un futuro, el segundo es dar la máxima difusión a los artículos publicados y aumentar el interés por publicar en esta revista; y el tercero es dotar a la RICMA de los avances y beneficios de las nuevas tecnologías.

Para que una revista sea indexada es necesario que cumpla ciertos requisitos, sin duda uno de los más importantes es el rigor y la calidad científica, tanto de los artículos publicados como del proceso editorial. Este punto no es difícil de conseguir, ya que los anteriores comités editoriales de la RICMA, se han encargado de crear una publicación "peer-review", en la que todos los artículos son evaluados de forma ciega por dos especialistas reconocidos en Cirugía de la Mano y del Miembro Superior. En esta nueva etapa hemos adaptado las normas editoriales a los "Requisitos de uniformidad para el envío de artículos a revistas biomédicas" elaborados por el Comité Internacional de Editores de Revistas Médicas (ICMJE), disponibles en: http://www.icmje.org. También hemos modificado la estructura de la RICMA y se publicarán en este nuevo ciclo los siguientes tipos de artículos:

Editorial: artículo de opinión, redactado por el comité editorial, por el comité de antiguos directores o por un tercero al que se le solicite su colaboración.

Originales: trabajos inéditos sobre cualquier campo (clínico o experimental) en relación con la Cirugía y Microcirugía de la Extremidad Superior.

Casos clínicos: casos clínicos de "excepcional interés" en la Cirugía y Microcirugía de la Extremidad Superior. 
Técnicas quirúrgicas: técnicas quirúrgicas inéditas o explicación de técnicas conocidas, en las que sean de especial interés los "trucos" y detalles quirúrgicos aportados por el autor.

Artículos de actualización: trabajos de revisión y actualización sobre cualquier patología, técnica diagnóstica o quirúrgica de interés para la Cirugía y Microcirugía de la Extremidad Superior.

Artículos especiales: incluirán tanto las cartas al director como otro tipo de artículos de especial interés para las sociedades científicas (becas, premios, etc).

Otro punto fundamental para que una revista sea indexada es la puntualidad en la publicación y para conseguirlo es necesario el interés de los autores en remitir artículos. Es decir, la puntualidad en la publicación, se enlaza con el segundo objetivo que nos planteamos; el dar la máxima difusión a la RICMA. Entendemos que cuantos más autores tengan acceso a la RICMA, más interés despertará en ellos la publicación y sabrán que su artículo será leído por un gran número de cirujanos, que comparten su especialización.

Para conseguir esta máxima difusión, queremos que la RICMA tenga colaboración científica con el mayor número de sociedades de cirugía de mano posibles. En esta nueva etapa la SociedadVenezolana de Cirugía de Mano se une al proyecto como sociedad afiliada y queremos expresarle nuestro agradecimiento y bienvenida a este proyecto.

También queremos que sea una revista abierta, on-line y gratuita. Estamos convencidos (al igual que PUBMED y otras muchas sociedades científicas), que la ciencia debe ser lo más "universal" posible y que las publicaciones "abiertas" se deben favorecer. Por eso en esta nueva etapa y de acuerdo con la SECMA, la revista se publicará on-line, en una web específica.

La publicación on-line y abierta sin duda hará que el número de lectores aumente, pero en esta época de nuevas tecnologías y cambios radicales en las formas de comunicación, no podemos dar de lado a las redes sociales, que tienen un potencial de difusión cada vez mayor y cuyo número de usuarios crece exponencialmente año tras año. Por eso acabamos de incorporar a la RICMA a diversas redes sociales.

Nuestro último objetivo, aunque ya lo hemos mencionado al hablar de la difusión de la revista, es hacer de la RICMA una revista moderna, con una página web específica que posea las características positivas de una "web 2.0" y por la que se pueda navegar fácilmente desde cualquier dispositivo móvil (teléfono, ipad, tablets, etc.). Muestra de ello es la inauguración hoy de está web: www.reviberoamericanamano.org.

Para terminar, agradecer una vez más el trabajo de todos los profesionales que han formado y forman parte de la RICMA y esperar que esta nueva etapa continúe e incluso aumente el interés por la RICMA, ya que para conseguir una revista de referencia en la cirugía de la mano es fundamental la participación de todos nosotros, no solo como lectores, sino también como autores. 